\title{
SWOT Analysis and Design of Flipped Classroom of Accounting Informationization Curriculum
}

\author{
Beibei Wen ${ }^{1, a^{*}}$, Yuanyuan Zhao ${ }^{1, b}$ and Lei Wang ${ }^{1, c}$ \\ ${ }^{1}$ Chengdu Neusoft University, Du Jiangyan, Sichuan, China \\ a'Wenbeibei@nsu.edu.cn, ${ }^{\mathrm{a}} Z$ haoYuanyuan@nsu.edu.cn, ${ }^{\mathrm{T}}$ Wang.Lei@nsu.edu.cn
}

Keywords: Accounting informationization; Flipped teaching; SWOT; Model

\begin{abstract}
This paper adopts SWOT analysis and conducts an integrated study on flipped teaching in the course of accounting informationization. It is believed that flipped teaching is quite feasible in the course of accounting informationization. The paper works out the framework of the flipped teaching, designs a teaching model and conducts feature analysis on the model. At last, the paper puts forward some innovative understandings on training practical accounting informationization talents.
\end{abstract}

\section{Introduction}

Course of Accounting Informationization. Accounting computerization has replaced the original manual accounting. Now jobs can be done with accounting software, but the efficiency and accuracy get higher. Accounting computerization will be a development trend in the future, and the research on it has become increasingly important for finance and accounting majors. For classroom teaching, popular accounting software is usually selected as the operational platform [1]. Students are guided to practice the business process by module on the platform. Students get familiar with the software operation and understand the business process after the financial operations. With the application of manual book-keeping knowledge to computer operation, students know the method of manual book-keeping; what's more, they can advance with the times and handle the operation of financial software well.

Flipped Teaching. Flipped teaching originated from America. It is a bold attempt of Salman Khan and other two American teachers based on long-term practice. Very good teaching effects were achieved at last. The new model has been recognized by the world and got promoted. It has totally subverted the traditional teaching model. Besides, it has brought about new ideas and significances to outside-class teaching and in-class knowledge internalization, as shown in Fig. 1.

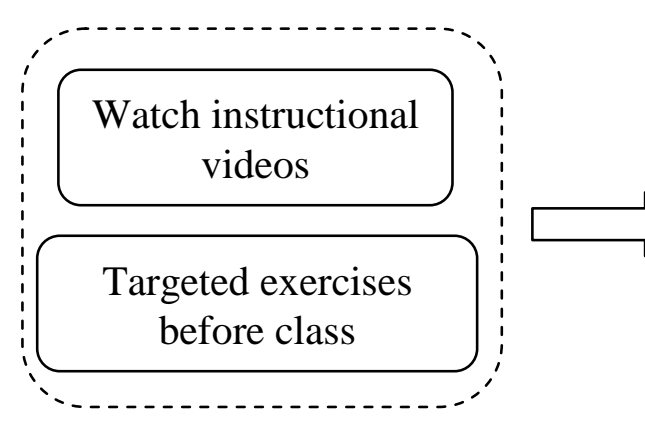

Pre-class knowledge transfer

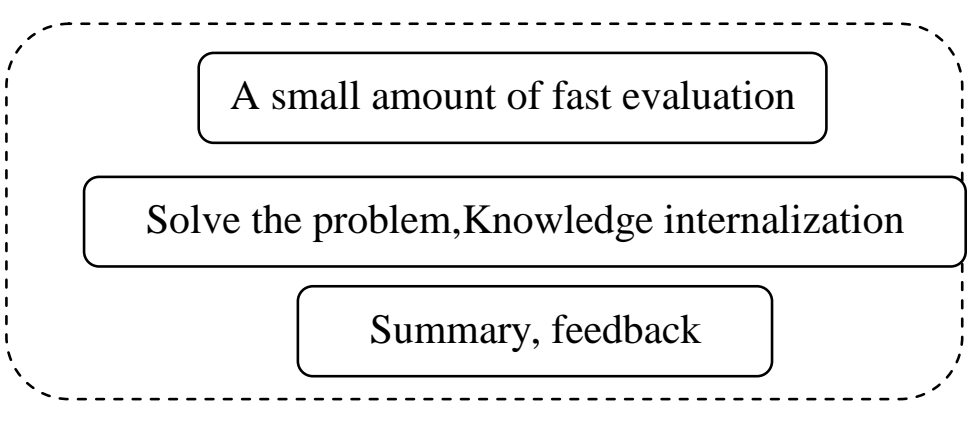

Knowledge internalization in class

Figure 1. The flipped classroom model of Robert Talbert

\section{SWOT Analysis on Application of Flipped Teaching in Accounting Informationization Course}

Strengths and Weaknesses (SW). Accounting informationization is one of the courses most suitable for flipped teaching [2]. Traditional accounting informationization courses are given based on the background of industrial enterprises. There are numerous software modules, including general 
accounting module, financial management module (including UFO statement, salary, fixed assets, receivables \& payables, etc) and supply chain module (purchase, sales, stock, inventory, etc.). Limited by class hours, teachers have to wait for students to finish their operation in addition to teaching and demonstrating. As a result, the class advances slowly. There are few case exercises in each link in order to save time. Moreover, some teaching modules have to be discarded, and most teachers choose to reduce the supply chain modules or pass them. According to students, they have to follow the operation of the teacher. There are barely enough time for them to think carefully about the principles. With the weak understandings and poor memories, they are unable to complete the exercises on their own.

In flipped teaching, knowledge-transference mainly relies on videos. Accounting informationization stresses operation particularly, and with videos, every operation procedure of the teacher can be recorded for students to watch and learn after school [3]. They can record their questions and reflect them to the teacher for the whole class to seek a common solution. Teachers are relieved, for the contents they have to teach are greatly reduced. There is enough time to record videos about accounting informationization concerning other industries and share them with students. So students can do incremental learning selectively according to their own needs and have the applied range extended. On the other hand, students can voluntarily arrange their time for spare-time study and thinking; they can control the video progress and times of replay; and they can consolidate and review the teaching focuses. In addition, students can communicate face on their questions to face with the teacher in class. Thus the efficiency of traditional remote after-school guide can be raised.

The concept of flipped classroom has been introduced to China not long ago. It emerged abroad in 2007 and got popular in 2011 [4]. Although it has been well received overseas, most Chinese educationalist attached little importance till 2012. At present, the experiment teaching has been popularized only in middle and primary school. Flipped education focusing on higher education is still in the stage of theoretical study or small-class experiment. Neither has it been supported by mass data nor has there any significant successful experience for reference. To break the current domestic classroom teaching model for higher education, it is necessary to import flipped teaching. Colleges, teachers and students must reach a consensus and accept the new teaching model. They must have confidence in the effect of flipped teaching and spare no effort to promote its improvement. And all this work is arduous.

Opportunities and Threats (OT). According to the Ten-year Development of Educational Informationization (2011-2020) of China, the development of educational informationization should be guided by innovative educational ideas; it should be based on the construction of high-quality educational resources and learning environment, with learning styles and educational model innovation as the core [5].

At present, guaranteed by the improvement of domestic economy and internet technology, the technological base required by the implement of flipped teaching is available. Computer intellectual terminal technology is necessary for both teachers and students in flipped classrooms, with notebook and mobile phone as the learning tools. As it were, flipped learning is an option to bring forth new ideas to traditional classroom teaching. It is as well a necessary product of era development. In short, the integrated application of these technologies has built a digital learning environment and resources for flipped teaching [6].

It is for sure that with the policy and technical support guaranteed by this time, step by step, numerous difficulties have to be faced and overcome in practice. Colleges and universities should invest to build information cloud platform, gather gigantic information resources for students to screen and use, and build good feedback mechanism. Besides, schools should provide professional video producing software or laboratories, which can facilitate teachers in producing excellent videos. On the other hand, educational teams should be built. Teachers' personal professional competence must be strengthened so as to avoid student baffling during discussions. What's more, members of the educational teams must pool their wisdom. Videos produced by them should be refined, focused, interesting and able to arouse the enthusiasm of students. As for students, since flipped teaching 
requires strong self-study ability, they must make reasonable time arrangement. In extra-curricular time, they must spend more time watching videos and thinking. Information feedback between students and teachers is required too.

\section{Flipped Teaching Model Design for Accounting Informationization Course}

Flipped Teaching Model for Accounting Informationization. The flipped teaching model for accounting informationization is as shown in Fig. 2:

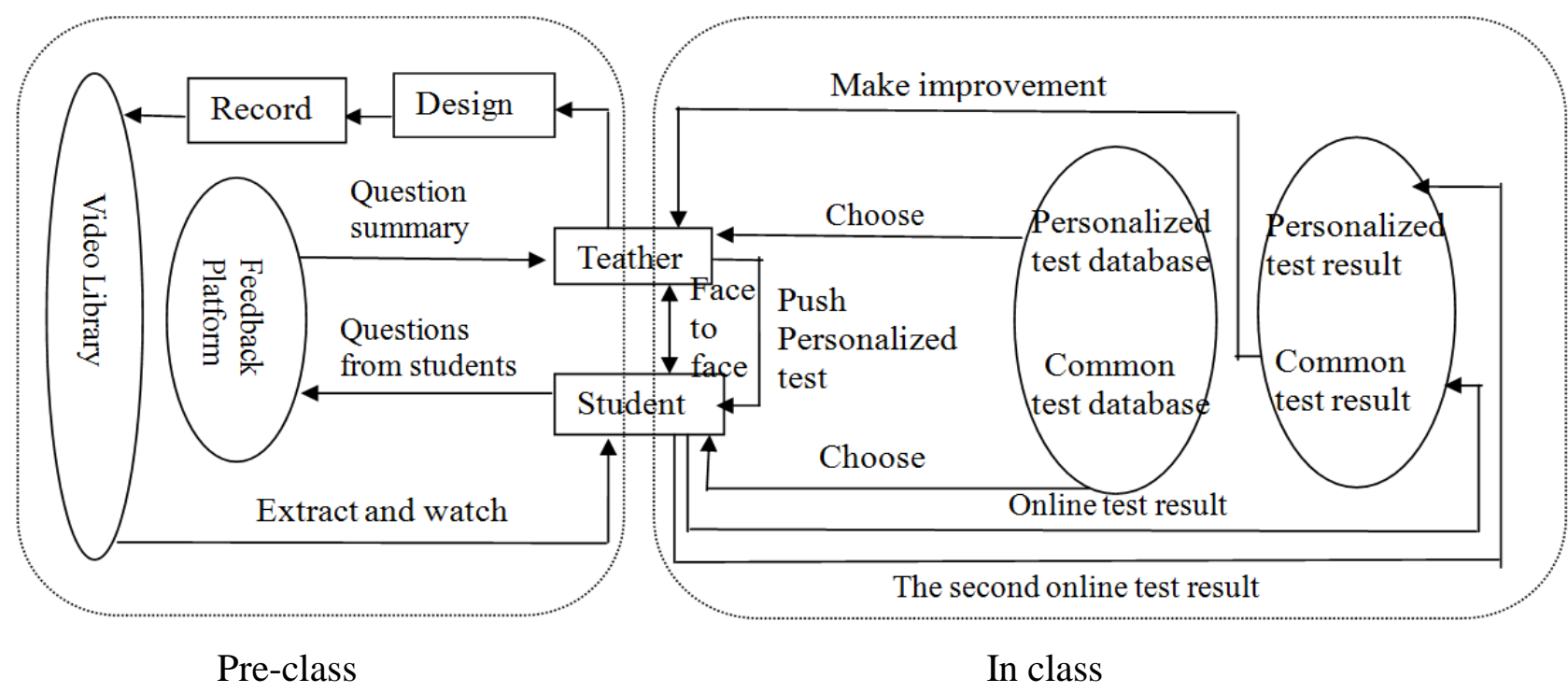

Figure 2. The flipped classroom model of Robert Talbert

Model Design Features. Rich material \& comprehensive information. Inside the school a material cloud platform should be built, including video database, item bank and feedback platform. Videos in the database must be around 15 minutes and displayed by the category of case guide. Take the teaching of sales management as an example. Videos can be produced in accordance with sales business types, which are nine, including sales initialization, sales with delivery before billing, sales with billing before delivery, direct consignment sales, installment sales, retail business, goods return in delivery before billing, goods return in delivery upon billing and sales account analysis. Each video should start with a topic of business processing; the content should focus on the process of business processing; there should be an operation flow chart at the end summarizing the relationship between the previous and the follow-up operation, so students can comprehend and understand it. The video database is mainly consists of curricular learning and extracurricular learning. The former should be recorded as required by the teaching program and syllabus within the context of industrial enterprise; the latter involves the accounting of enterprises engaged in hot industries, such as real estate, construction and commodity circulation. Students can take them as elective courses according to their own needs [6]. The item bank on the cloud platform can also be divided into two levels: general items and personalized items. The former provides basic test items [7]. Drawn by students themselves during the class, they help teachers to check students' video learning before class. On the basis of primary test results, personalized item bank are pushed correspondingly by teachers to different levels of students.

The feedback platform mainly consists of external feedback and internal feedback. External feedback platform build a bond graduates. On the one hand, graduates' employment trend can be acquired; on the other hand, the real social demand for informationization talents and their operational skills can be learnt, which will help teachers to adjust the course contents and teaching orientation of accounting informationization. Internal feedback platform can be divided into two too. One is extracurricular information feedback, including students' questions in autonomic video watching 
before class. Teachers can prepare corresponding instructions based on these questions; the other is test result feedback. Teachers can check students' test results at any time and know the knowledge they have acquired.

Personalized supply \& individualized teaching. Multi-level teaching is an important feature of flipped class. Aiming at different levels of students, the flipped teaching model for accounting informationization can realize multi-level teaching in three ways. First of all, flipped teaching classroom significantly increases the time of face-to-face discussions between teachers and student. Teachers get plenty of time to reinforce classroom activities. For instance, they can answer questions intensively referred to by students on the platform. For questions raised by students with good receptivity and advanced learning tasks, teachers also have the time to discuss, analyze and provide solutions. In this way, students can make greater progress in study.

Second, in class, students can draw general items from the item bank to have small tests. Teachers can obtain the test results from the feedback platform immediately. They can group students by their test results. For instance, students scoring above 80 marks, 70 marks and 69 marks can be divided into different groups. Teachers draw items from the personalized item bank by group and assign them to different groups. Students must finish the test based on teamwork. Corresponding course tasks should be provided to students based on the different levels. The item complexity should be appropriate. Roles are assigned to group members by themselves. Then in discussion, they can display their respective advantages to communicate and make efforts together. There should be leveling in test question setting. For example, multiple team questions with stepped difficulties can be set for top students. Once a question of certain difficulty is solved, a more difficult one can be pushed by the teacher as a challenge. Teachers can attend the groups randomly or take part in the team discussion when students encounter problems. Through the joint discussion and problem-solving, students can advance in the level.

At last, teachers must pay attention to students' respective advantages in classroom interaction. Competent students can be recommended to watch videos in the supplementary video database, so they can extend their learning scope and promote their personal abilities.

Closed-loop environment \& win-win teaching. An important feature of the flipped teaching model for accounting informationization is the closed-loop environment. Teachers and students can achieve a win-win situation with it.

Improvement of video producing: Most initial videos are designed based on teachers' teaching experience and questions raised by students of previous years. After questions are raised by students after video watching, teachers can check the most frequently raised ones and change the instruction within correspondingly. Thus the question-answering in class can be further shortened and the videos get optimized. There will be more time for group discussion. Extracurricular videos can integrate the feedback information from the graduate platform and internal students in their self-learning. Video instructions details and omissions concerning different industrial aspects can be adjusted. Thus the needs of both this age and students can be met.

Improvement of item bank: General item banks are designed for all students. The primarily set contents may not be well-rounded. They need to be updated and supplemented gradually as the teaching process advances. Common problems encountered by students in learning will be explored step and step and added in the item banks. Personalized questions will also be taken into account, so everyone can think of a solution together. The more intensive the questions, the more likely students promote their problem-solving abilities. Personalized item banks are set for differently leveled students on a one-to-one basis. Items of this bank are more difficult. Students in the same class are differently leveled, so their potentials for advancement and learning requirements should be matured. The difficulty increasing and the application range extending of the personalized item bank should be performed according to students' test results.

After three rounds of the flipped teaching for accounting informationization, based on three batches of students' feedbacks and discussions, the teacher team will have a better understanding of students' requirements and questions they may encounter in learning. Teachers will become more 
proficient in class or group discussion. The contents of designed videos and items will be optimized and more specific. Moreover, with the strong support of the material library, students will become goal-directed in learning. Their ability of problem-solving in teamwork and discussion with the teacher will be promoted too.

\section{Difficulties in Implementation of Flipped Teaching in Accounting Informationization}

A considerable number of problems need to be solved to guarantee the smooth implementation of flipped teaching in accounting informationization courses. Things are always hardest at the beginning. The application of flipped teaching to accounting informationization courses is a new attempt. It must be implemented with the concerted effort of the school and students. Firstly, the school must build a cloud platform and provide unblocked network [8]. It will be convenient for teachers and students to upload feedback information after school. The school should also provide the teacher team with technical support in video producing, so the video quality can be guaranteed. Secondly, instead of accomplishing the mission when the class is dismissed, in their spare time, teachers must spend more time on video database and item bank producing and improving. They should check information at any time on the feedback platform; they should know students' trend, collect their questions and supplement their own knowledge. In this way, they can answer students' questions in discussion promptly and effectively. At last, students have increased learning tasks after school too. More of their spare time must be spent on learning. It requires higher self-discipline and initiative. These issues are all very challenging [9]. Only with full cooperation of all involved parties can the effects of flipped teaching be shown well.

Additionally, there is one more issue worthy of attention: construction of the course assessment. The assessment of flipped teaching can no longer be confined to the points-based measurement system. To formulate an assessment system, which gives full consideration to students' comprehensive learning ability before, in and after class, is a critically important link.

In conclusion, the development of flipped teaching in accounting informationization courses has just begun [10]. More education researchers are required to take part in and practice. With more suggestions and implemental experience from them, the better development of accounting informationization courses can be promoted.

\section{Acknowledgements}

General Item of Humanities and Social Sciences of Education Department of Sichuan (2015SB0265)

\section{References}

[1] L.H. Yu: China Economic and Trade, (2012) No.5, p.54-55. (In Chinese)

[2] S.See and J.M. Conry: Currents in Pharmacy Teaching \& Learning, (2014) NO.6, p585-588.

[3] Information on http://www.cssn.cn/jyx/jyx_jyjsx/201504/t20150409_1580039.shtml

[4] J. Bergmann and A. Sams: Flip your classroom: Reach every student in every class every day. (International Society for Technology in Education, American 2012).

[5] C. Li and G.H. Liu: China Educational Technology and Equipment, (2013) NO.5, p.82-83. (In Chinese)

[6] T. Unruh, M. L. Peters and J. Willis: Computers in the Schools Interdisciplinary Journal of Practice Theory \& Applied Research, (2016), p38-58.

[7] Z.J. Sun, M. Zhang. and T. Zou: Pharmacy Education, (2012) NO.8, p.60-62. (In Chinese)

[8] X. Chen: Employment of Chinese College Students, (2010) NO.6, p.24-25. (In Chinese) 
[9] J. Hargis and S.M. Marotta: Active Learning in Higher Education, (2011) NO.12, p35-44.

[10] H. Wang, H.W. Gao and G.S. Ma: Enterprises in Hebei, (2014) NO.10, p95-97. (In Chinese) 